\title{
First Report of Leishmania tropica from a Classical Focus of L. major in North-Sinai, Egypt
}

\author{
Magdi G. Shehata, Abdallah M. Samy, Said A. Doha, Adel R. Fahmy, Rania M. Kaldas, \\ Barry D. Furman, and Jeffrey T. Villinski* \\ Entomology Department, Faculty of Science, Ain Shams University, Cairo, Egypt; Research and Training Centers \\ on Vectors of Diseases, RTC, Faculty of Science Building, Ain Shams University, Cairo, Egypt; \\ Vector Biology Research Program, U.S. Naval Medical Research Unit No. 3, Cairo, Egypt
}

\begin{abstract}
Cutaneous leishmaniasis (CL) is prevalent in the Egyptian Sinai Peninsula and previous research has consistently documented the etiologic agent to be Leishmania major. We report the first isolation of Leishmania tropica from human cases of CL in a Northern Sinai community bordering Palestine. Parasite culturing, real-time polymerase chain reaction (PCR), gene sequencing, and restriction fragment length polymorphism (RFLP) analyses indicate CL cases in this community were caused by either L. major or L. tropica (three cases each). Two wild-caught rodents (Gerbillus pyramidum floweri) were infected with L. tropica. Phlebotomus papatasi sand flies were found harboring L. major, however only non-infected individuals of Phlebotomus sergenti, a vector for L. tropica, were caught. Patients with $L$. tropica had not traveled from the region in over a year, suggesting these cases are autochthonous. This scenario is consistent with an incursion of L. tropica from bordering countries and raises concerns about expansion of this parasite further into Egypt.
\end{abstract}

\section{INTRODUCTION}

Cutaneous leishmaniasis (CL) is an important health problem in many parts of the world, especially Mediterranean and Middle East countries. In these regions, CL is typically caused by one of two species of Leishmania parasite: L. major or L. tropica. Clinical symptoms of both infections are similar, producing ulcerative and nodular lesions. Lesions, particularly from L. major, typically self-heal within several months in immune-competent patients and injection with intra-lesional antimonals is an often prescribed treatment of both parasites. Similarities notwithstanding, differentiating between these agents is important for several reasons, including a more complete understanding of the geographic distribution and prevalence of these parasites. Disease control strategies may require customization to target the sand fly vector and mammalian reservoir host responsible for transmission of each parasite. Infection by $L$. tropica may confer cross-immunity to reinfection by other Leishmania spp., including L. major. ${ }^{1}$ Most importantly, infection by L. tropica can cause visceral leishmaniasis and leishmaniasis recidivans, serious pathologies that require a modified treatment regimen., ${ }^{2,3}$

Cutaneous leishmaniasis is endemic to the Sinai region of Egypt, and, when the etiologic agent was identified, L. major has been the culprit parasite. ${ }^{4-6}$ Leishmania major is a zoonotic parasite. In the Sinai, parasites are transferred to humans from infected rodent reservoir hosts (Meriones crassus and Gerbillus pyramidum) by the bite of the sand fly vector Phlebotomus papatasi. ${ }^{4-9}$ Although localities may differ in the species of mammalian host (e.g., West Bank, Jericho: Psammomys obesus, Isfahan province, Iraq: Rhombomys opimus), $P$. papatasi is the principal sand fly vector throughout the Mediterranean basin, Middle East, Central Asia, and East Africa. ${ }^{10,11}$

Leishmania tropica also occurs widely in the Middle East. The transmission cycle for L. tropica is usually anthroponotic with zoonotic transmission reportedly occurring in some areas. ${ }^{12-16}$ Rock hydraxes may serve as the reservoir species in Israel (Procavia capensis) and Kenya (P. johnstoni). ${ }^{16,17}$ Phlebotomus sergenti is an oft implicated sand fly vector in both transmis-

*Address correspondence to Jeffrey T. Villinski, Vector Biology Research Program, U.S. Naval Medical Research Unit No. 3, PSC 452 Box 141, FPO AE 09835, USA. E-mail: jeff.villinski@.med.navy.mil sion scenarios and can be found along the Mediterranean coast from Libya, through Egypt, Jordan, Israel, and Iraq. ${ }^{18}$ Egypt is not a known focus for L. tropica, although there are some old reports from the Nile Delta region. ${ }^{19}$ The only recent Egyptian case of CL definitively attributed to L. tropica was an infection acquired outside of Egypt by a worker returning from Saudi Arabia. ${ }^{20}$

In September 2006, physicians from El Barth community hospital (near Rafah, Northern Sinai, Egypt) collected case histories and tissue biopsies from 10 patients with suspected CL. Using culture methods, the Ain Shams University Research and Training Center (RTC) verified the presence of Leishmania in six of these samples. The RTC also surveyed the local sand fly fauna to identify vector species, and successfully cultured or visually observed Leishmania from lesions of 14 wild-caught rodents. The RTC subsequently contacted the U.S. Naval Medical Research Unit No. 3 (NAMRU-3), Cairo, to determine the species identity in Leishmania-positive cultures. Our final results verified the pathogens, vector, and potential reservoir involved in the leishmaniasis disease cycle in the study area as follows: 1) human cases of CL were caused by either L. major or L. tropica,2) known sand fly vectors of both parasites were identified, and 3) wild-caught rodents harbored Leishmania parasites, including two Gerbillus pyramidum floweri infected with L. tropica.

\section{MATERIALS AND METHODS}

Study site. The community of El Barth is located $35 \mathrm{~km}$ southeast of $\operatorname{Rafah}\left(31^{\circ} 01^{\prime} \mathrm{N}, 34^{\circ} 12^{\prime} \mathrm{E}\right.$ to $\left.30^{\circ} 8^{\prime} \mathrm{N}, 34^{\circ} 17^{\prime} \mathrm{E}\right)$ on the El Ghoora road and has $\sim 5,000$ inhabitants. Rafah is a remote location on the Egyptian border with Palestine (Figure 1) and is inhabited principally by Bedouins. El Barth community is divided into four sectors (Kilo 25, Kilo 30, Kilo 33, and Kilo 36) located along the Egyptian-Palestinian border.

Sand fly collection and processing. Sand flies were collected over 5 days in December 2006, and 10 days in May 2007, using sticky traps and Centers for Disease Control and Prevention (CDC) light traps (John W. Hock, Gainesville, FL). Two collection stations were randomly selected in each of the four sectors to place sticky and light traps and a total of 100 (25 in each sector) sticky traps were distributed. Recovered traps were placed in labeled plastic bags and transported to 


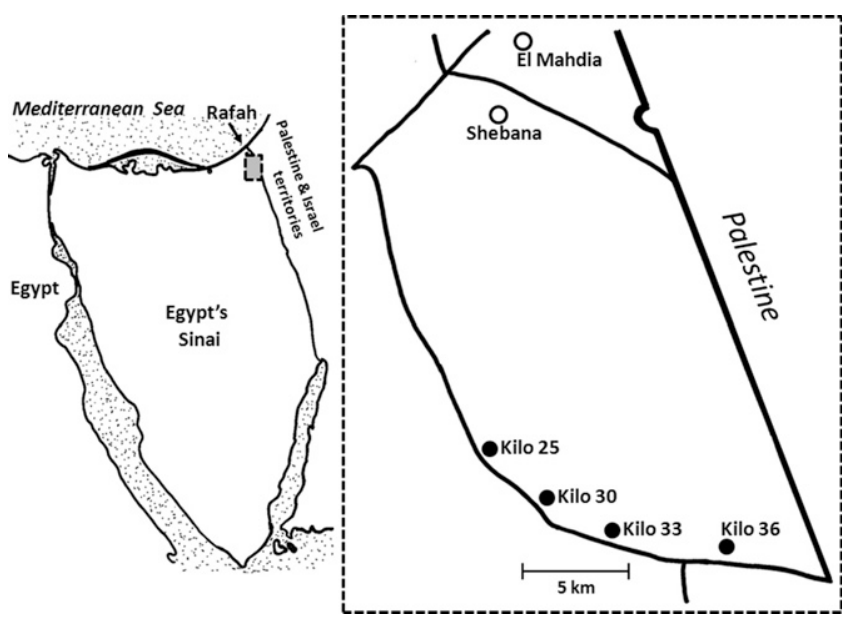

Figure 1. Regional and local map (dashed box) of the study site in North-Sinai, Egypt. The four sectors of the El Barth community are denoted by black dots, roads are in black lines, and the border with Palestine indicated by a thick black line. Scale bar $=5 \mathrm{~km}$.

a temporary field laboratory in El Barth hospital. Dead flies were stored in $70 \%$ alcohol for species identification. Some live flies were used to initiate sand fly colonies, the remainder were dissected under sterile conditions for species identification via morphologic keys. ${ }^{21}$ Dissected flies suspected to harbor Leishmania promastigotes were processed for parasite isolation.

Rodent capture and identification. Rodents were collected from the study area during December 2006 and May 2007, using wire-box rodent traps placed adjacent to rodent burrows and inside houses. Five traps were placed in each of the four sectors for five nights during December, and 10 traps per sector for 10 nights in May for a total of 500 trap nights. Captured animals were identified using regional taxonomic keys, transported to an animal facility at the RTC, and maintained for at least 6 months to monitor for lesion development. ${ }^{22}$ Full-thickness punch-biopsies were removed from the border of suspected Leishmania lesions for parasite isolation. Impression smears were also taken from lesions and Giemsa stained to examine for Leishmania amastigotes. All care and use of animals followed guidelines stipulated by CIOMS International Guiding Principles for Biomedical Research Involving Animals. ${ }^{23}$

Sample collection from patients. In the North Sinai, Leishmania cases are typically present from August through October. In September 2006, physicians from El Barth Medical Health Unit collected tissue biopsies and case histories (patient age, gender, travel history, treatment history, and lesion description) from $10 \mathrm{El}$ Barth residents with suspected CL. Each patient first signed a consent form, and was then treated according to accepted international principles and guidelines (Declaration of Helsinki by the World Medical Association). After injection with a local anesthetic, punch biopsies were collected from the lesion periphery and transported to Ain Shams University for parasite isolation. According to local standard practice, physicians initiated, or continued, sodium stibogluconate (Pentostam, GlaxoSmithKline, London, UK) treatment of all patients after sample collection.

Parasite isolation and cultivation. Isolates inoculated with tissue samples were maintained in culture medium through subculture passages in Novy-MacNeal-Nicolle (NNN) culture medium with 500 IU penicillin G/mL of blood. Promastigotes from positive cultures were transferred to glass vials containing Schneider's Drosophila cell culture medium supplemented with $10 \%$ fetal calf serum (Sigma, Saint Louis, MO and Gibco-BRL, Gaithersburg, MD) for mass rearing.

Molecular characterization of Leishmania cultures. One $\mathrm{mL}$ of each high density $\left(\sim 1 \times 10^{6}\right.$ cells $\left.\mathrm{mL}^{-1}\right)$ Leishmania culture was concentrated by centrifugation and these pellets transported from the RTC to NAMRU-3 for species identification. The DNA was extracted from $25 \mu \mathrm{L}$ of each pellet using the Qiagen DNA Mini Kit (Qiagen, Valencia, CA), and stored at $-20^{\circ} \mathrm{C}$.

Real-time PCR, conventional PCR, DNA sequencing, sequence analysis, and restriction fragment length polymorphism (RFLP) analysis were preformed as previously described. ${ }^{24}$ Briefly, DNA extracts were screened for Leishmania DNA using primer-probe sets that cross-react among Leishmania spp., amplifying fragments of the small subunit rDNA (LEIS) or kinetoplast DNA (kDNA). Samples were also screened specifically for L. major. ${ }^{25-27}$ Each realtime PCR experiment included a positive control (DNA from a reference strain: L. major, IPAP/EG/89/SI-177 and L. tropica, WR664) and a negative control (water). The internal transcribed region (ITS1) of the small sub-unit ribosomal DNA was amplified from samples by conventional PCR and sequenced in both directions from four isolates using primers L5.8S and LITS.R. ${ }^{28}$ The DNA sequences were manipulated with BioEdit version 7.0.5.3 and used to query GenBank. ${ }^{29}$ The DNA sequences from this study and homologs from GenBank were aligned using BioEdit and imported into MEGA 4.0 for gene tree construction. ${ }^{30}$ Restriction fragment length polymorphism analysis of the ITS1 amplicons was performed on seven samples and two reference strains using the restriction enzyme HaeIII. ${ }^{31}$

\section{RESULTS}

Sand fly identification and parasite isolation. A total of 2,049 sand flies were identified to the species level (Table 1). Phlebotomus papatasi accounted for $82.1 \%$ (1138q 9,536 $\bar{\delta}$ ) of the identified flies and the remaining flies, $17.9 \%$, (169우, $206 \lesssim ふ$ ) were P. sergenti. Based on microscopy, seven P. papatasi had Leishmania-like flagellates in their midgut, of which four produced viable cultures identified as L. major (Table 2).

Rodent species. Eighty-one individuals from five rodent species were collected: Gerbillus pyramidum floweri $(N=29)$, G. andersoni $(N=26)$, Meriones sacramanti $(N=18)$, M. crasus $(N=7)$, and Mus musculus $(N=1)$. Of 25 rodents with cutaneous lesions, 19 (all of genus Gerbillus) produced positive amastigote smear tests and 14 (11 G. pyramidum floweri and $3 G$. andersoni) produced viable parasite cultures. Cultures from two $G$. pyramidum floweri were identified as L. tropica (samples 6 and 7) and the remaining rodent-derived cultures harbored L. major (Table 2, Figure 2).

Characteristics of patients with suspected CL. All 10 patients reported having not traveled outside of El Barth region in over 1 year. Lesions were localized to the extremities or other areas typically exposed fly bites. Leishmania parasites were successfully isolated and identified for six patients, three infected with L. major and three with L. tropica (Table 2, 
TABLE 1

The number of phlebotomine sand flies collected and identified from each of the four sectors of El Barth community of North-Sinai, Egypt. 2049 sandflies were identified as either Phlebotomus papatasi or $P$. sergenti and separated according to sex*

\begin{tabular}{lccccrrr}
\hline & \multicolumn{3}{c}{ P. papatasi } & & \multicolumn{3}{c}{ P. sergenti } \\
\cline { 2 - 4 } \cline { 6 - 8 } \multicolumn{1}{c}{ Sector } & F & M & Total & & F & \multicolumn{1}{c}{ M } & Total \\
\hline Kilo 25 & 346 & 158 & 504 & & 21 & 12 & 33 \\
Kilo 30 & 255 & 120 & 375 & & 81 & 135 & 216 \\
Kilo 33 & 358 & 146 & 504 & & 33 & 39 & 72 \\
Kilo 36 & 179 & 112 & 291 & & 34 & 20 & 54 \\
Grand total & 1138 & 536 & $\mathbf{1 6 7 4}$ & & 169 & 206 & $\mathbf{3 7 5}$ \\
& & & $(82.1 \%)$ & & & $(17.9 \%)$ \\
\hline
\end{tabular}

* Percentages indicate the proportion of sand flies of each species.

Figure 2); the remaining four suspected cases did not produce viable cultures. Case details (below) indicate L. major infection (cases 1-3) presented with wet lesions, and L. tropica (cases 4-6) presented with dry lesions, with no apparent correlation between number of lesions per patient and infective agent.

Case 1: A 3-year-old boy had a single, $0.9 \times 1.1 \mathrm{~cm}$, wet lesion located on the brow. No history of drug treatment. (MHOM/ EG/06/RTC-63; L. major).

Case 2: A 12-year-old boy had multiple wet lesions localized on both knees. Lesion size ranged between $1.1 \times 1.2 \mathrm{~cm}$ and
$1.9 \times 2.2 \mathrm{~cm}$. No history of drug treatment. $(\mathrm{MHOM} / \mathrm{EG} / 06 /$ RTC-64; L. major).

Case 3: A 35-year-old woman had multiple wet lesions distributed upward to thorax and neck area on front. Lesion size ranged between $0.8 \times 1 \mathrm{~cm}$ and $1.1 \times 1.3 \mathrm{~cm}$. No history of drug treatment. (MHOM/EG/06/RTC-65; L. major).

Case 4: A 13-year-old boy had multiple dry red crusted nodules or lesions localized on both feet. Lesions were $3.0 \times 2.0$ $\mathrm{cm}$ in size. No history of drug treatment. (MHOM/EG/06/ RTC-66; L. tropica).

Case 5: A 17-year-old boy had a single dry lesion on the right arm. Lesion size was $1.3 \times 1.7 \mathrm{~cm}$. There was no history of drug treatment of this mostly healed lesion. (MHOM/EG/06/ RTC-67; L. tropica).

Case 6: A 9-year-old boy with multiple dry lesions on the right foot. Lesions were similar in size $(3.0 \times 1.0 \mathrm{~cm})$. The patient reported a history of treating the lesions with sodium stibogluconate (Pentostam). (MHOM/EG/06/RTC-70; L. tropica).

Leishmania species identity. Twenty-four of 28 Sinai isolates were positive for Leishmania DNA using the LEIS primer-probe set, however, only 19 of these were also positive for L. major DNA (Table 2). The remaining five isolates (samples 4-8) were positive for Leishmania kDNA (data not shown), confirming the presence of Leishmania parasites.

TABLE 2

Real-time polymerase chain reaction (PCR), restriction fragment length polymorphism (RFLP), and DNA sequence analysis results*

\begin{tabular}{|c|c|c|c|c|c|c|c|}
\hline \multirow[b]{2}{*}{ Sample } & \multirow[b]{2}{*}{ Source } & \multirow[b]{2}{*}{ Isolate } & \multirow{2}{*}{$\frac{\text { LEIS }}{\mathrm{Ct}}$} & \multirow{2}{*}{$\frac{\text { L. major }}{\mathrm{Ct}}$} & \multirow[b]{2}{*}{ RFLP } & \multirow[b]{2}{*}{ Sequence } & \multirow[b]{2}{*}{ Conclusion } \\
\hline & & & & & & & \\
\hline 1 & Human case 1 & MHOM/EG/06/RTC-63 & 28.25 & 34.00 & - & - & L. major \\
\hline 2 & $", 2$ & MHOM/EG/06/RTC-64 & 27.32 & 32.54 & L. major & L. major & L. major \\
\hline 3 & $"=3$ & MHOM/EG/06/RTC-65 & 27.30 & 37.22 & L. major & - & L. major \\
\hline 4 & $", 4$ & MHOM/EG/06/RTC-66 & 26.00 & ND & L. tropica & L. tropica & L. tropica \\
\hline 5 & $", 5$ & MHOM/EG/06/RTC-67 & 25.57 & ND & L. tropica & L. tropica & L. tropica \\
\hline 8 & $" " 6$ & MHOM/EG/06/RTC-70 & 24.00 & ND & L. tropica & - & L. tropica \\
\hline 9 & $", 7$ & MHOM/EG/06/RTC-71 & ND & - & - & - & ND \\
\hline 10 & $"=8$ & MHOM/EG/06/RTC-72 & ND & - & - & - & ND \\
\hline 11 & $", 9$ & MHOM/EG/06/RTC-68 & ND & - & - & - & ND \\
\hline 12 & $" » 10$ & MHOM/EG/06/RTC-69 & ND & - & - & - & ND \\
\hline 6 & G. pyramidum 1 & MGER/EG/06/RTC-73 & 25.27 & ND & L. tropica & L. tropica & L. tropica \\
\hline 7 & $" 2$ & MGER/EG/06/RTC-74 & 27.17 & ND & L. tropica & - & L. tropica \\
\hline 14 & $"=3$ & MGER/EG/07/RTC-76 & 31.00 & 37.97 & - & - & L. major \\
\hline 16 & $", 4$ & MGER/EG/07/RTC-79 & 29.70 & 36.23 & - & - & L. major \\
\hline 21 & $" " 5$ & MGER/EG/07/RTC-80 & 26.70 & 37.84 & - & - & L. major \\
\hline 22 & $" ” 6$ & MGER/EG/07/RTC-81 & 26.02 & 33.70 & - & - & L. major \\
\hline 23 & $", 7$ & MGER/EG/07/RTC-82 & 26.81 & 35.70 & - & - & L. major \\
\hline 24 & $" \# 8$ & MGER/EG/07/RTC-84 & 26.75 & 34.68 & - & - & L. major \\
\hline 26 & $"=9$ & MGER/EG/07/RTC-85 & 19.70 & 27.63 & - & - & L. major \\
\hline 27 & $" » 10$ & MGER/EG/07/RTC-86 & 21.55 & 29.56 & - & - & L. major \\
\hline 28 & $", 11$ & MGER/EG/07/RTC-96 & 21.94 & 29.91 & - & - & L. major \\
\hline 13 & G. andersoni 1 & MGER/EG/06/RTC-75 & 30.87 & 38.00 & - & - & L. major \\
\hline 15 & $"{ }^{\prime} 2$ & MGER/EG/07/RTC-77 & 29.90 & 36.23 & - & - & L. major \\
\hline 25 & $"=3$ & MGER/EG/07/RTC-83 & 21.26 & 28.97 & - & - & L. major \\
\hline 17 & P. papatasi 1 & IPAP/EG/07/RTC-87 & 25.04 & 35.25 & - & - & L. major \\
\hline 18 & $", 2$ & IPAP/EG/07/RTC-89 & 25.50 & 34.00 & - & - & L. major \\
\hline 19 & $" \# 3$ & IPAP/EG/07/RTC-90 & 26.09 & 37.24 & - & - & L. major \\
\hline 20 & $", 4$ & IPAP/EG/07/RTC-93 & 23.04 & 33.71 & - & - & L. major \\
\hline Control & L. major & IPAP/EG/89/SI-177 & 18.45 & 22.23 & L. major & - & L. major \\
\hline Control & L. tropica & WR664 & 15.56 & ND & L. tropica & - & L. tropica \\
\hline
\end{tabular}

*A total of 28 samples were cultured from individuals of four source organisms. Isolates were named according to standard nomenclature (e.g., isolate MHOM/EG/06/RTC-63 was cultured from a human sample [MHOM)] obtained in Egypt [EG] during the 2006 calendar year [06] by the Ain Shams University Research and Training Center [RTC] and assigned a unique identifier [63]). Real time PCR cycle threshold values (Ct) are reported for experiments using the LEIS and L. major primer-probe sets. The RFLP analysis was performed on DNA from 7 samples and DNA sequenced from 4 samples. The Leishmania species identification assigned to each sample is recorded as the Conclusion. ND indicates where target DNA was not detected; experiments not preformed are indicated by a dashed line (-). 


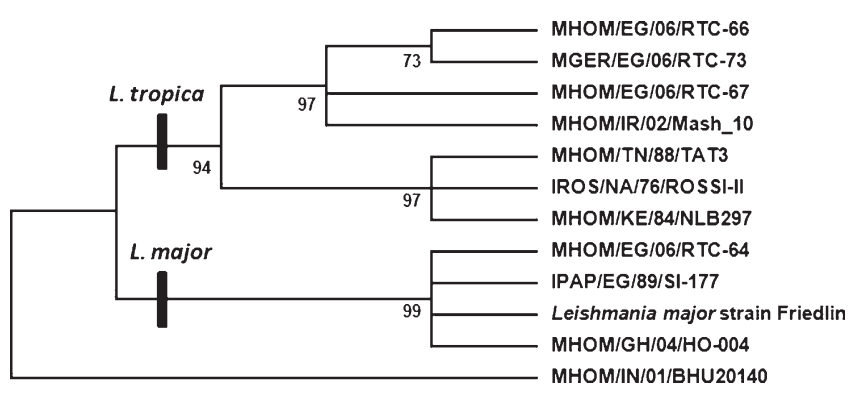

FIGURE 2. Dendrogram constructed using Leishmania major, $L$. tropica, and $L$. donovani ITS1 polymerase chain reaction (PCR) fragment sequences. Between 221-238 bp of the ITS1-5.8S rRNA region from representative isolates were aligned and a gene tree constructed using maximum parsimony. Bootstrap analysis was performed with 500 replicates and bootstrap $P$ values reported at nodes. Black bars delineate the base of each clade for L. tropica and L. major. Strains (accession no.) for L. tropica were those from this study (MHOM/EG/06/RTC-66 (FJ460457), MHOM/EG/06/RTC67 (FJ460459), MGER/EG/06/RTC-73 (FJ460458), and others from GenBank:MHOM/IR/02/Mash_10(EF653267), MHOM/TN/88/TAT3 (AJ300485), IROS/NA/76/ROSSI-II (AJ000302), MHOM/KE/84/ NLB297 (AJ000301). Leishmania major strains included one from this study, MHOM/EG/06/RTC-64 (FJ460456), and from GenBank: IPAP/EG/89/SI-177 (DQ295824), Leishmania major strain Friedlin (70799905), MHOM/GH/04/HO-004 (DQ295825). Leishmania donovani strain MHOM/IN/01/BHU20140 (AJ634378) was included as an out group.

The ITS1 DNA sequences were obtained for samples 2 (accession FJ460456), 4 (FJ460457), 5 (FJ460459), and 6 (FJ460458). Sample 2 was confirmed as L. major; the sequence is identical to several L. major sequences deposited in GenBank, including isolates from Iran, Kenya, and the Sinai. Samples 4 and 6 were identical and differed from sample 5 at 3 of 322 nucleotides. These samples had the highest overall BLAST similarity to a L. tropica strain from Sudan $(97 \%$ identity, MHOM/SU/60/OD). A maximum parsimony gene tree constructed with these sequences and homologues from GenBank shows a tight clustering of $L$. major sequences, including sample 2, and a looser, but definitive clustering of samples 4-6 with other L. tropica sequences (Figure 2). Phylogenetic analysis yielded a single best tree when using maximum parsimony, 500 bootstraps, and a complete deletion of gaps; the 348 nucleotide alignment had 33 parsimony informative sites. The Sinai L. tropica sequences ally most closely to an Iranian isolate (MHOM/IR/02/Mash_10), principally because of shared similarity at the 3 end of the fragment. The RFLP analysis supports these results. Samples 2 and 3 and the L. major reference DNA produced fragments characteristic of L. major, whereas samples $4-8$ and the L. tropica reference DNA had the pattern typical for L. tropica (Figure 3). ${ }^{31}$

\section{DISCUSSION}

The goal of this study was to identify the etiologic agent responsible for recent cases of $\mathrm{CL}$ in $\mathrm{El}$ Barth community. Efforts were also made to identify the sand fly vectors and sylvan reservoirs. The Northern Sinai is a classic focus of Leishmania major, and three of the patients examined were indeed infected by this parasite. However, lesions from three other patients (young boys 9, 13, and 17 years of age) were infected with L. tropica, and they represent the first identification of this species in the area. Because of the mobile nature of the Bedouin community, travel histories were collected

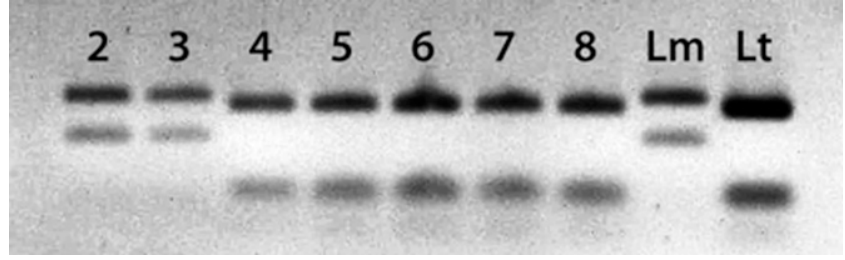

FIGURE 3. Restriction fragment length polymorphism (RFLP) analysis of ITS1 polymerase chain reaction (PCR) fragments amplified from culture isolates and control DNA, and then digested with HaeIII. Numbers (2-8) represent the sample source (Table 2). Control DNA sources were L. major $(\mathrm{Lm})$ and L. tropica $(\mathrm{Lt})$.

to assess the likelihood that patients currently residing in El Barth contracted leishmaniasis from neighboring countries with high disease incidence. ${ }^{20}$ The parents of these patients reported that the young boys had not traveled from the community within the past year. Because lesions from L. tropica typically manifest within a few months of infection, these self-reports are consistent with an infection acquired within El Barth; however, we cannot exclude the formal possibility of sub-clinical infections contracted during travel from more than 1 year ago.

Competing scenarios can account for the presence of L. tropica in this focal area of L. major. The geographic distribution of L. tropica may simply be greater than previously thought. Historical difficulties in distinguishing between L. major and L. tropica, coupled with a low disease burden, may have masked the presence of this parasite from past discovery despite significant surveillance for CL in the area. Alternatively, our observations may indicate a comparatively recent incursion by L. tropica from adjacent regions of high endemicity. Such has been observed in Jericho, Israel, where, in an area endemic for L. major, human CL cases attributed to L. tropica have recently emerged. ${ }^{15,32,33}$ Unfortunately, the molecular data do not clarify the issue. Phylogenetic analysis indicates that the ITS1 sequences from L. tropica in Sinai ally most closely with an Iranian isolate, and were significantly divergent from two geographically proximate strains from Israel (GenBank accession nos. EU683617 and EU683618). ${ }^{34}$ Although this finding could be used to support the first scenario, the high intra-specific genetic diversity of L. tropica must be explicitly accounted for when attempting to reconstruct molecular epidemiology and population genetics..$^{33,35}$ Without a more clear relationship between the Sinai L. tropica and other isolates, we cannot conclusively distinguish between alternative explanations; however, efforts to more accurately determine the distribution and genotypes of this parasite in the Sinai are underway.

The presence of L. tropica in Sinai raises two concerns for disease management in Egypt: is the parasite population stable in Sinai? Will it spread to other areas of Egypt? To persist, Leishmania requires a reservoir and a competent vector to transmit the parasite. The life cycle of L. major in the Sinai involves rodent hosts, including G. pyramidum floweri and $G$. andersoni as identified in this study, and the sand fly vector, Phlebotomus papatasi. The occasional zoonotic transfer of L. major to humans likely has little impact on the population stability of this parasite. The same may not be true for L. tropica because the transmission cycle varies between localities and generally does not require a sylvan reservoir. Leishmania 
tropica is transmitted anthroponotically in Afghanistan by P.sergenti but in Israel and Kenya is suspected to have a zoonotic transmission cycle with $P$. sergenti transmitting parasites among populations of rock hyraxes and humans. ${ }^{16,17} \mathrm{We}$ have not fully clarified the transmission cycle in the Sinai; however, L. tropica was isolated from rodents leaving open the possibility of zoonotic transmission. Phlebotomus sergenti accounted for $\geq 17 \%$ of sand flies captured in El Barth. Determining the parasite transmission cycle (zoonotic or anthroponotic) will be critical for disease prevention. If the transmission cycle is anthroponotic, control efforts targeting a non-human reservoir would have little effect, but reducing household level exposure to sand flies (e.g., insecticide-treated bednets) would be appropriate. Regardless, it is apparent that El Barth region has preconditions for a stable presence of L. tropica.

Risk factors such as increased agriculture, urbanization of rural areas, and environmental changes influence the geographic distribution of CL by altering the distribution of the vector, the reservoir host, or the frequency of contact with humans. ${ }^{36}$ Humans, the sand fly vector, and a potential reservoir are already widely distributed along Egypt's northern coast, suggesting that L. tropica could potentially spread within Egypt without any change in risk factors. ${ }^{20,22,37}$ This same concern has been raised for L. major, whose sand fly vector and mammalian reservoir co-occur elsewhere in Egypt. Thus far, L. major has been restricted to the Sinai region and it is currently thought that geographic variation in vectorial competency limits parasite distribution. ${ }^{38}$ Phlebotomus sergenti is also refractory to infection by different populations of L. tropica. ${ }^{33}$ Without further study, it is not clear what barriers exist to prevent L. tropica from extending within the country from this newly documented focal point in El Barth.

\section{Received January 25, 2009. Accepted for publication March 31, 2009.}

Acknowledgments: We thank Shabaan El-Hossary and Hany Kamal, Research and Training Centers on Vectors of Diseases, (RTC) for their help during the field study and Awni Farag, El Barth local Hospital, MoHP, Rafah Northern Sinai, for supporting patient sample collections. Comments from Dr. Bode greatly improved the manuscript.

Financial support: Molecular analyses were supported by grants to NAMRU-3.

Disclosure: Two field trips to the study site, collection of sand flies, animals, and maintenance Leishmania parasites and animals at the RTC were supported by Ain Shams University. Clinical investigations and Leishmania parasite isolation protocols were approved by the Ain Shams University IRB and were conducted in accord with the international regulations and guidelines of the Declaration of Helsinki (World medical association declaration of Helsinki: Ethical Principles for Medical Research Involving Human Subjects). Every patient first signed a consent form. Care and use of animals followed the Animal guidelines of CIOMS 1985. The last three authors are employees of the U.S. Government and Title 17 U.S.C. $\$ 105$ provide that "Copyright protection under this title is not available for any work of the United States Government." Title 17 U.S.C. \$101 defines a U.S. Government work as a work prepared by a military service member or employee of the U.S. Government as part of that person's official duties.

Disclaimer: The views expressed in this article are those of the authors and do not necessarily reflect the official policy or position of the Department of the Navy, Department of Defense, the U.S. Government, or the Egyptian Government.

Authors' addresses: Magdi G. Shehata, Abdallah M. Samy, Said A. Doha, and Adel R. Rahmy, Department of Entomology, Faculty of
Science, Ain Shams University, Abbassia, Cairo 11566, Egypt, Tel: +2-02-2482-1096 ext. 442, Fax: +2-02-2482-1096, E-mails: mgdshehata@yahoo.com,drabedooo@hotmail.com,doha57@yahoo.com, and arfahmy@gmail.com. Rania M. Kaldas, Barry D. Furman, and Jeffrey T. Villinski, Vector Biology Research Program, U.S. Naval Medical Research Unit No. 3, PSC 452 Box 141, FPO AE 09835, USA, Tel: +2-02-2348-0279, Fax: +2-02-2342-3090, E-mails: Rania.Kaldas.eg@ med.navy.mil, Barry.Furman@med.navy.mil, and jeff.villinski@.med navy.mil.

\section{REFERENCES}

1. Porrozzi R, Teva A, Amaral VF, Santos da Costa MV, Grimaldi G Jr, 2004. Cross-immunity experiments between different species or strains of Leishmania in Rhesus Macaques (Macaca mulatta). Am J Trop Med Hyg 71: 297-305.

2. Magill AJ, Grogl M, Gasser RA Jr, Sun W, Oster CN, 1993. Visceral infection caused by Leishmania tropica in veterans of operation Desert Storm. N Engl J Med 328: 1383-1387.

3. Alborzi A, Rasouli M, Shamsizadeh A, 2006. Leishmania tropicaisolated patient with visceral leishmaniasis in southern Iran. Am J Trop Med Hyg 4: 306-307.

4. Mansour NS, Fryauff DJ, Modi GB, Mikhail EM, Youssef FG, 1991. Isolation and characterization of Leishmania major from Phlebotomus papatasi and military personnel in north Sinai, Egypt. Trans R Soc Trop Med Hyg 85: 590-591.

5. Dawoud HA, 2004. Identification of cutaneous leishmaniasis in Egypt by hybridization of PCR amplified mini-exon repeats. J Egypt Soc Parasitol 34: 881-892.

6. Kamal HA, Doha SA, El-Hossary SS, Shehata MG, El Sawaf BM, 2003. Human zoonotic cutaneous leishmaniasis and associated sand flies (Diptera: Psychodidae) in Sheikh Atiya village, southern Sinai, Egypt. J Egypt Soc Parasitol 33: 795-803.

7. Morsy TA, Salama MM, Saleh MS, 1991. Leishmania major and Meriones crassus in North Sinai Governorate, Egypt. J Egypt Soc Parasitol 21: 337-342.

8. Morsy TA, Shoukry A, Schnur LF, Sulitzeanu A, 1987. Gerbillus pyramidum is a host of Leishmania major in the Sinai Peninsula. Ann Trop Med Parasitol 81: 741-742.

9. Fryauff DJ, Modi GB, Mansour NS, Kreutzer RD, Soliman S, Youssef FG, 1993. Epidemiology of cutaneous leishmaniasis at a focus monitored by the multinational force and observers in the northeastern Sinai Desert of Egypt. Am J Trop Med Hyg 49: 598-607.

10. Schlein Y, Warburg A, Schnur LF, Le Blancq SM, Gunders AE, 1984. Leishmaniasis in Israel: reservoir hosts, sandfly vectors and Leishmania 1 strains in the Negev, Central Arava and along the Dead Sea. Trans R Soc Trop Med Hyg 78: 480-484.

11. Parvizi P, Benlarbi M, Ready PD, 2003. Mitochondrial and Wolbachia markers for the sandfly Phlebotomus papatasi: little population differentiation between peridomestic sites and gerbil burrows in Isfahan province, Iran. Med Vet Entomol 17: 351-362.

12. Jacobson RL, 2003. Leishmania tropica (Kinetoplastida: Trypanosomatidae)-a perplexing parasite. Folia Parasitol (Praha) 50: 241-250.

13. Garifallou A, Schnur LF, Stratigos JD, Hadziandoniou M, Savigos M, Stavrianeas N, Sérié C, 1984. Leishmaniasis in Greece II. Isolation and identification of the parasite causing cutaneous leishmaniasis in man. Ann Trop Med Parasitol 78: 369-675.

14. Mebrahtu YB, Lawyer PG, Ngumbi PM, Kirigi G, Mbugua J, Gachihi G, Wasunna K, Pamba H, Sherwood JA, Koech DK, 1992. A new rural focus of cutaneous leishmaniasis caused by Leishmania tropica in Kenya. Trans $R$ Soc Trop Med Hyg 86: 381-387.

15. Jacobson RL, Eisenberger CL, Svobodova M, Baneth G, Sztern J, Carvalho J, Nasereddin A, El Fari M, Shalom U, Volf P, Votypka J, Dedet JP, Pratlong F, Schonian G, Schnur LF, Jaffe CL, Warburg A, 2003. Outbreak of cutaneous leishmaniasis in northern Israel. J Infect Dis 188: 1065-1073.

16. Sang DK, Njeru WK, Ashford RW, 1992. A possible animal reservoir for Leishmania tropica s.l. in Kenya. Ann Trop Med Parasitol 86: 311-312. 
17. Svobodova M, Votypka J, Peckova J, Dvorak V, Nasereddin A, Baneth G, Sztern J, Kravchenko V, Orr A, Meir D, Schnur LF, Volf P, Warburg A, 2006. Distinct transmission cycles of Leishmania tropica in 2 adjacent foci, Northern Israel. Emerg Infect Dis 12: 1860-1868.

18. Seccombe AK, Ready PD, Huddleston LM, 1993. A catalogue of Old World phlebotomine sandflies (Diptera: Psychodidae, Phlebotominae). Occas Pap Syst Entomol 8: 1-57.

19. Cahill KM,1965. Leishmania skin testing in Africa and the Middle East. East Afr Med J 42: 213-220.

20. Mohareb EW, Mikhail EM, Youssef FG, 1996. Leishmania tropica in Egypt: an undesirable import. Trop Med Int Health 1: 251-254.

21. Lane RP, 1986. The sand flies of Egypt (Diptera: Phlebotominae). Bull Br Mus Nat Hist Entomol 52: 1-35.

22. Osborn DJ, Helmy I, 1980. Mammals of Egypt. Chicago: Field Museum of Natural History, 1-579.

23. CIOMS, 1985. International Guiding Principles for Biomedical Research Involving Animals. Altern Lab Anim 12: ii.

24. Villinski JT, Klena JD, Abbassy MM, Hoel DF, Puplampu N, Mechta S, Boakye D, Raczniak G, 2008. Evidence for a new species of Leishmania associated with a focal disease outbreak in Ghana. Diagn Microbiol Infect Dis 60: 323-327.

25. Wortmann G, Sweeney C, Houng H-S, Aronson N, Stiteler J, Jackson J, Ockenhouse C, 2001. Rapid diagnosis of leishmaniasis by fluorogenic polymerase chain reaction. Am J Trop Med Hyg 65: 583-587.

26. Mary C, Faraut F, Lascombe L, Dumon H, 2004. Quantification of Leishmania infantum DNA by real-time PCR assay with high sensitivity. J Clin Microbiol 42: 5249-5255.

27. Wortmann G, Hochberg L, Houng H-H, Sweeney C, Zapor M, Aronson N, Weina P, Ockenhouse CF, 2005. Rapid identification of Leishmania complexes by a real-time PCR assay. Am J Trop Med Hyg 73: 999-1004.

28. El Tai NO, Osman OF, El Fari M, Presber W, Schönian G, 2000. Genetic heterogeneity of ribosomal internal transcribed spacer (ITS) in clinical samples of Leishmania donovani spotted on filter paper as revealed by single-strand conformation polymorphisms (sscp) and sequencing. Trans R Soc Trop Med Hyg 94: $1-5$.
29. Hall TA, 1999. BioEdit: a user-friendly biological sequence alignment editor and analysis program for Windows 95/98/NT. Nucleic Acids Symp Ser 41: 95-98.

30. Kumar S, Tamura K, Nei M, 2004. MEGA3: integrated software for molecular evolutionary genetics analysis and sequence alignment. Brief Bioinform 5: 150-163.

31. Schönian G, Nasereddin A, Dinse N, Schweynoch C, Schallig HDFH, Presber W, Jaffe CL, 2003. PCR diagnosis and characterization of Leishmania in local and imported clinical samples. Diagn Microbiol Infect Dis 47: 349-358.

32. Al-Jawabreh A, Schnur LF, Nasereddin A, Schwenkenbecher JM, Abdeen Z, Barghuthy F, Khanfar H, Presber W, Schonian G, 2004. The recent emergence of Leishmania tropica in Jericho (A'riha) and its environs, a classical focus of L. major. Trop Med Int Health 9: 812-816.

33. Schnur LF, Nasereddin A, Eisenberger CL, Jaffe CL, El Fari M, Azmi K, Anders G, Killick-Kendrick M, Killick-Kendrick R, Dedet JP, Pratlong F, Kanaan M, Grossman T, Jacobson RL, Schonian G, Warburg A, 2004. Multifarious characterization of Leishmania tropica from a Judean desert focus, exposing intraspecific diversity and incriminating Phlebotomus sergenti as its vector. Am J Trop Med Hyg 70: 364-372.

34. Nasereddin A, Bensoussan-Hermano E, Schonian G, Baneth G, Jaffe CL, 2008. Molecular diagnosis of Old World cutaneous leishmaniasis and species identification by use of a reverse line blot hybridization assay. J Clin Microbiol 46: 2848-2855.

35. Schonian G, Schnur LF, El Fari M, Oskam L, Kolesnikov AA, Sokolowska-Kohler W, Presber W, 2001b. Genetic heterogeneity in the species Leishmania tropica revealed by PCR-based methods. Trans R Soc Trop Med Hyg 95: 217-224.

36. Desjeux P, 2001. The increase in risk factors for leishmaniasis worldwide. Trans R Soc Trop Med Hyg 95: 239-243.

37. Morsy TA, El-Missiry AG, Kamal AM, Fayad ME, El-Sharkawy IM, 1990. Distribution of Phlebotomus species in the Nile delta, Egypt. J Egypt Soc Parasitol 20: 589-598.

38. Hanafi HA, el Sawaf BM, Fryauff DJ, Beavers GM, Tetreault GE, 1998. Susceptibility to Leishmania major of different populations of Phlebotomus papatasi (Diptera: Psychodidae) from endemic and non-endemic regions of Egypt. Ann Trop Med Parasitol 92: 57-64. 